\title{
PENGARUH MODEL PEMBELAJARAN BERBASIS MASALAH PADA MATERI LISTRIK DINAMIS TERHADAP HASIL BELAJA SISWA DI SMA NEGERI 1 KUALUH LEIDONG T.A 2015/2016
}

\author{
Togi Tampubolon*) dan Royarti Tamba **) \\ (Prodi Pendidikan Fisika FMIPA Unimed) \\ *) Dosen Fisika Unimed \\ **) Mahasiswa Pendidikan Fisika Unimed \\ tambaroyarti@yahoo.co.id
}

\begin{abstract}
ABSTRAK
Penelitian ini bertujuan untuk mengetahui pengaruh model pembelajaran berbasis masalah terhadap hasil belajar siswa pada materi listrik dinamis di kelas X SMA Negeri 1 Kualuh Leidong. Jenis penelitian ini adalah quasi exsperiment. Pengambilan sampel dilakukan dengan cara cluster random sampling dengan mengambil 2 kelas yaitu kelas X-1 berjumlah 31 orang sebagai kelas eksperimen dan kelas X-2 berjumlah 31 orang sebagai kelas kontrol. Instrumen yang digunakan dalam penelitian ini adalah tes hasil belajar yang berbentuk essay test dan aktivitas siswa dengan menggunakan lembar observasi. Berdasarkan hasil penelitian diperoleh nilai rata-rata hasil belajar siswa yang diberi perlakuan model pembelajaran berbasis masalah adalah 67,82 dan pembelajaran konvensional adalah 59,52. Peningkatan aktivitas belajar siswa selama mengikuti pembelajaran dengan menggunakan model pembelajaran berbasis masalah dari pertemuan I sampai III dengan rata- rata nilai seluruhnya adalah 62,07 dengan kriteria penilaian aktif. Berdasarkan hasil analisis perhitungan uji t, terdapat perbedaan yang signifikan akibat pengaruh model pembelajaran berbasis masalah untuk meningkatkan hasil belajar siswa pada materi listrik dinamis di kelas X SMA Negeri 1 Kualuh Leidong T.A 2015/2016.
\end{abstract}

Kata Kunci : Model pembelajaran berbasis masalah, hasil belajar, aktivitas.

\begin{abstract}
This study aims to determine the effect of problem based learning to student learning outcomes in a dynamic electrical material in class X SMA Negeri 1 Kualuh Leidong. This research is a quasi exsperiment. Sampling was done by cluster random sampling by taking two classes, namely class X-1 amounted to 31 people as an experimental class and class X-2 amounted to 31 people as a control group. The instrument used in this study is the achievement test in the form of essay test and student activity by using the observation sheet. The research showed the average value of student learning outcomes by treatment of problembased learning model is 67.82 and the conventional learning is 59.52. Increased student activity during the learning with the use of problem-based learning model of meetings I to III with an average of 62.07 with the total value is active assessment criteria. Based on the results of the analysis of the t test calculation, there are significant differences due to the effects of problem based learning to improve student learning outcomes in a dynamic electrical material in class $X$ SMA Negeri 1 Kualuh Leidong T.A 2015/2016.
\end{abstract}

Keywords: problem-based learning model, learning outcomes, activity. 


\section{PENDAHULUAN}

Pendidikan pada hakekatnya adalah usaha sadar dan terencana untuk mewujudkan suasana belajar dan proses pembelajaran agar peserta didik secara aktif mengembangkan potensi dirinya untuk membentuk watak serta peradaban bangsa yang bermartabat agar menjadi manusia yang beriman dan bertakwa kepada Tuhan Yang Maha Esa, berakhlak mulia, berilmu, kreatif, mandiri, dan menjadi warga Negara yang demokratis serta bertanggung jawab, menurut UUSPN No. 20 tahun 2003 (Abdullah, 2013: 60). Pengajaran merupakan perpaduan antara dua aktifitas, yaitu aktifitas mengajar dan aktifitas belajar. Aktifitas mengajar menyangkut peranan seorang guru dalam konteks mengupayakan terciptanya jalinan komunikasi yang harmonis antara mengajar itu sendiri dengan belajar (Trianto, 2010).

\begin{tabular}{ccc}
\multicolumn{2}{c}{ Bidang studi sains } & fisika \\
sebagai bagian & dari & Ilmu
\end{tabular} Pengetahuan Alam (IPA) merupakan objek mata pelajaran yang menarik dan lebih banyak memerlukan pemahaman dari pada penghafalan. Kenyataannya fisika sering dipandang sebagai suatu ilmu yang abstrak oleh siswa dengan teori dan soal-soal yang sulit.

Berdasarkan hasil wawancara yang dilakukan oleh peneliti kepada seorang guru bidang studi fisika di SMA Negeri 1 Kualuh Leidong, beliau mengatakan bahwa hasil belajar fisika siswa masih rendah. Kriteria paling rendah untuk menyatakan peserta didik mencapai KKM (Kriteria Ketuntasan Minimal) pada mata pelajaran fisika ditetapkan di sekolah adalah 75, tetapi hanya $33 \%$ siswa saja di tiap kelas yang mampu mencapai nilai diatas 75 dan $67 \%$ siswa masih dibawah 75 . Hasil angket juga diperoleh bahwa kegiatan belajar dikelas masih berpusat pada guru, guru hanya menjelaskan dipapan tulis, siswa mencatat materi, mengerjakan soal. Hal lainnya ketika guru bertanya kepada siswa apakah materi yang disampaikan tersebut bisa dimengerti, siswa sebagian besar hanya diam saja dengan kata lain tidak ada siswa yang memberikan jawaban yang pasti. Hal serupa juga juga terjadi ketika suatu kali guru memberikan demonstrasi, siswa juga kurang aktif dalam pelaksanaannya. Hal ini menunjukkan siswa hanya menerima pengetahuan dari guru saja tanpa berinisiatif menemukan sendiri bagaimana menyelesaikan masalah dari soal yang diberikan guru tersebut.

Berbagai masalah yang peneliti jumpai, peneliti merasa perlu adanya suatu pembelajaran yang membuat siswa aktif dalam kelas, melibatkan seluruh siswa dalam proses pembelajaran yang berorientasi pada pembelajaran yang berpusat pada siswa dengan mengangkat fenomena fisika yang lebih autentik dalam kehidupan sehari-hari. Serta yang paling penting adalah adanya suatu peningkatan hasil belajar siswa tersebut. Tentu dengan menggunakan model pembelajaran yang mendukung.

Berdasarkan kenyataan tersebut, perlu diterapkan suatu model pembelajaran yang sesuai dan mampu meningkatkan aktivitas dan hasil belajar fisika siswa. Salah satu alternatif model pembelajaran yang memungkinkan diterapkan adalah model pembelajaran berbasis 
masalah. Model pembelajaran berbasis masalah merupakan pendekatan yang efektif untuk pengajaran proses berpikir tingkat tinggi (Trianto, 2010). Pembelajaran model pembelajaran berbasis masalah dikembangkan untuk membantu siswa mengembangkan kemampuan berpikir, pemecahan masalah dan keterampilan intelektual, belajar berbagai peran orang dewasa melalui perlibatan mereka dalam pengalaman nyata dan menjadi pebelajar yang otonom dan mandiri.

Berdasarkan uraian di atas penulis tertarik untuk melakukan penelitian dengan tujuan untuk mengetahui hasil belajar siswa dengan menggunakan model Pembelajaran Berbasis Masalah pada materi Listrik Dinamis kelas $\mathrm{X}$ semester II SMA Negeri 1 Kualuh Leidong T.P 2015/2016.

\section{METODE PENELITIAN}

Penelitian ini dilaksanakan di SMA Negeri 1 Kualuh Leidong dengan populasi seluruh siswa kelas $X$ SMA Negeri 1 Kualuh Leidong yang terdiri dari enam kelas. Teknik pengambilan sampel dilakukan dengan cara teknik sampel kelas acak (cluster random sampling). Sampel kelas diambil dari populasi sebanyak dua kelas yaitu kelas X-1 berjumlah 31 orang dengan menggunakan model pembelajaran berbasis masalah dan kelas X-2 berjumlah 31 orang dengan menggunakan pembelajaran konvensional. Jenis penelitian ini adalah kuasi eksperimen ini dengan desain two group pretest-postest design seperti yang ditunjukkan pada Tabel 1 .
Tabel 1. Desain Penelitian tipe Two Group Pretest-Postest

\begin{tabular}{lccc}
\hline \multicolumn{1}{c}{ Kelas } & Pretes & Perlakuan & Postes \\
\hline Eksperimen & $Q_{1}$ & $X_{1}$ & $Q_{2}$ \\
\hline Kontrol & $Q_{1}$ & $X_{2}$ & $Q_{2}$ \\
\hline
\end{tabular}

Keterangan:

$Q_{1}=$ pemberian tes awal kepada kelas eksperimen dan kelas kontrol

$Q_{2}=$ pemberian tes akhir kepada kelas eksperimen dan kelas kontrol

$X_{1}=$ model pembelajaran berbasis masalah

$X_{2}=$ pembelajaran konvensional

Alat pengumpul data dalam penelitian ini adalah tes berbentuk uraian untuk mengetahui hasil belajar siswa dan lembar observasi untuk mengetahui aktivitas selama proses pembelajaran.

Uji hipotesis yang digunakan dengan menggunakan uji t dengan membandingkan rata-rata skor hasil belajar yang dicapai baik kelas eksperimen maupun kelas kontrol. Data yang diperoleh ditabulasikan kemudian dicari rata-ratanya. Sebelum dilakukan penganalisisan data, terlebih dahulu ditentukan skor masing-masing kelompok sampel lalu dilakukan pengolahan data dengan langkah-langkah sebagai berikut: a) Menghitung nilai rata-rata dan simpangan baku, b) Uji normalitas, c) Uji homogenitas, d) Uji kesamaan rata-rata pretes, e) Pengujian hipotesis.

\section{HASIL PENELITIAN DAN PEMBAHASAN}

\section{Hasil Penelitian}

Penelitian diawali dengan memberikan pretes untuk mengetahui hasil belajar pada ranah pengetahuan. Hasil pretes kelas 
eksperimen memperoleh nilai ratarata 31,85 dan nilai rata-rata kelas kontrol adalah 29,11. Hasil data normal dan kesamaan rata-rata pretes ditunjukkan pada Tabel 2.

Tabel 2. Hasil data normal dan kesamaan rata-rata pretes.

\begin{tabular}{|l|l|l|l|}
\hline Kelas & $\begin{array}{l}\text { Ra- } \\
\text { rata }\end{array}$ & $\mathbf{t}_{\text {hitung }}$ & $\mathbf{t}_{\text {tabel }}$ \\
\hline Eksperimen & 31,85 & 1,53 & 2,00 \\
\hline Kontrol & 29,11 & 1,53 & 2,00 \\
\hline $\begin{array}{l}\text { Kesimpulan : } \\
\text { Kemampuan awal siswa } \\
\text { sama }\end{array}$ \\
\hline
\end{tabular}

Berdasarkan Uji Liliefors dimana Ltabel > Lhitung sehingga data berdistribusi normal. Berdasarkan Uji Homogenitas dimana Ftabel > Fhitung sehingga data berdistribusi homogen. Berdasarkan Uji t dua pihak data pretes kedua kelas tidak ada perbedaan secara signifikan, maka pada kedua kelas sampel diberikan perlakuan yang berbeda, pada kelas eksperimen diberikan perlakuan dengan menerapkan model pembelajaran berbasis masalah sedangkan pada kelas kontrol diberikan perlakuan dengan menerapkan pembelajaran konvensional.

Setelah diberikan perlakuan yang berbeda, kedua kelas diberikan postes untuk melihat adanya perbedaan akibat penerapan model pembelajaran yang berbeda. Hasil rata-rata postes kelas eksperimen memperoleh nilai rata- rata 67,82 , sedangkan nilai rata-rata postes kelas kontrol adalah 59,52. Hasil data normal dan hipotesis siswa ditunjukkan pada Tabel 3.
Tabel 3. Hasil data normal dan kesamaan rata- rata postes

\begin{tabular}{|l|l|l|l|}
\hline Kelas & $\begin{array}{l}\text { Ra- } \\
\text { rata }\end{array}$ & $\mathbf{t}_{\text {hitung }}$ & $\mathbf{t}_{\text {tabel }}$ \\
\hline Eksperimen & 67,82 & 2,99 & 1,67 \\
\hline Kontrol & 59,52 & 2,99 & 1,67 \\
\hline Kesimpulan : & \\
Ada perbedaan \\
signifikat \\
\hline
\end{tabular}

Berdasarkan Uji t satu pihak data postes kedua kelas normal, ada perbedaaan yang signifikan akibat pengaruh penerapan model pembelajaran berbasis masalah terhadap hasil belajar siswa.

Hasil perkembangan aktivitas siswa kelas eksperimen dapat ditunjukkan pada Tabel 4.

Tabel 4. Penilaian Aktivitas Siswa pada Pertemuan I, II dan III

\begin{tabular}{|l|l|l|l|}
\hline Kelas & $\begin{array}{l}\text { Pert } \\
\text { I }\end{array}$ & $\begin{array}{l}\text { Pert } \\
\text { II }\end{array}$ & $\begin{array}{l}\text { Pert } \\
\text { III }\end{array}$ \\
\hline Eksperimen & $57 \%$ & $59 \%$ & $62 \%$ \\
\hline
\end{tabular}

Berdasarkan Tabel 4 dapat dilihat bahwa peningkatan aktivitas siswa di kelas eksperimen selama menerima pembelajaran dengan menggunakan model pembelajaran berbasis masalah ada peningkatan dalam kriteria aktif.

Penilaian aktivitas di kelas kontrol tidak ada penilaian karena siswa tidak melakukan praktek.

\section{Pembahasan}

Berdasarkan perolehan nilai rata-rata pretes siswa di kelas eksperimen sebesar 31,85 dan nilai rata-rata postes sebesar 67,82. Sedangkan di kelas kontrol diperoleh nilai rata-rata pretes siswa sebesar 29,11 dan nilai rata-rata postes 
sebesar 59,52 dan diperoleh thitung $>$ $t_{\text {tabel }}=(2,99>1,67)$ maka dapat disimpulkan bahwa $\mathrm{H}_{0}$ ditolak dan $\mathrm{H}_{\mathrm{a}}$ diterima.

Berdasarkan data nilai pretes dan postes beserta nilai aktivitas belajar siswa pada kelas eksperimen diperoleh bahwa siswa yang memiliki kriteria pretes sangat kurang, kriteria aktivitas aktif dan kriteria postes baik.

Berdasarkan penelitian ini, penggunaan model pembelajaran berbasis masalah dapat meningkatkan hasil belajar siswa dan aktivitas siswa karena model pembelajaran berbasis masalah. Model pembelajaran berbasis masalah merupakan pendekatan yang efektif untuk pengajaran proses berpikir tingkat tinggi (Trianto, 2010). Pembelajaran model pembelajaran berbasis masalah dikembangkan untuk membantu siswa mengembangkan kemampuan berpikir, pemecahan masalah dan keterampilan intelektual, belajar berbagai peran orang dewasa melalui perlibatan mereka dalam pengalaman nyata dan menjadi pembelajar yang otonom dan mandiri.

Berdasarkan

peneliti

terdahulu oleh (1) Kuo-shu Huang

(2012) hasil penelitian ini memberikan implikasi praktis untuk penerapan dan kemungkinan dalam pemanfaatan model pembelajaran berbasis masalah di kelas bahasa Asing. Terutama, siswa termotivasi dan self-prestasi keduanya mencapai tingkat yang signifikan (2) Mariani, dkk (2014) pada siswa kelas VIII SMP 1 Salatiga, hasil uji kemampuan belajar pada siswa di kelas eksperimen telah mencapai kriteria ketuntasan maksimal. Kemampuan spasial dalam percobaan siswa kelas eksperimen lebih tinggi dari kelas kontrol. (3) Turnip dan Maidita (2014) di SMA Negeri 1 Selesai memberikan perlakuan yang berbeda, kelas eksperimen dengan model pembelajaran berbasis masalah dan kelas kontrol dengan pembelajaran konvensional mengakibatkan hasil belajar di kelas eksprimen mengalami peningkatan yang signifikan. (4) Setyorini, dkk (2011), berdasarkan hasil penelitian dapat disimpulkan bahwa model pembelajaran berbasis masalah dapat meningkatkan kemampuan berpikir kritis pada siswa. Hal ini dapat dilihat bahwa $75 \%$ siswa memiliki kemapuan berpikir kritis, 7,5\% siswa memiliki kemapuan sangat kritis, psikomotorik siswa memiliki nilai rerata $82,75 \%$ dalam kategori sangat aktif dan efektif siswa mempunyai nilai rerata sebesar 73,38 yang termasuk dalam kategori baik. 
Kendala yang dalam pembelajaran, misalnya pada saat mengerjakan LKS, siswa dibagi dalam kelompok yang hanya beranggotakan 6 sampai 7 orang siswa, mengerjakan LKS selama 30 menit, masih terdapat siswa yang kurang aktif terlihat pada siswa dituntut untuk berdiskusi dalam melakukan percobaan, ada beberapa siswa yang memilih duduk diam dan menunggu hasil yang diperoleh oleh temannya daripada gabung membantu temannya untuk memperoleh data tersebut, hal ini dikarenakan kebiasaan siswa yang belum terbiasa dalam bekerjasama dalam belajar.

Model ini akan lebih baik apabila siswa terlibat aktif selama proses belajar melalui kerja kelompok, maka sebaiknya perlu menambahkan beberapa observer agar pembelajaran lebih terarah dan terawasi dalam pengumpulan data. Peneliti juga mengalami kesulitan dalam mengalokasikan waktu pada saat siswa mengajukan hasil diskusinya sehingga tidak semua kelompok dapat menyajikan hasil diskusinya, model ini akan lebih baik apabila peneliti mempertimbangkan pembagian waktu setiap fasenya secara efisien.

Harapan yang terkandung dalam model ini belum semuanya tercapai dengan hasil yang sangat baik, adapun faktor yang menyebabkan kondisi ini terjadi adalah siswa belum terbiasa diajarkan dengan menggunakan model pembelajaran berbasis masalah sehingga butuh penyesuaian dengan siswa saat proses pembelajaran berlangsung. Oleh sebab itu, hendaknya dalam proses pembelajaran sebaiknya siswa diajarkan dengan menggunakan model pembelajaran yang lebih variatif supaya siswa mampu memahami materi pelajaranpelajaran fisika secara efektif dan efisien.

Berdasarkan hasil penelitian dan pengujian hipotesis dapat dilihat bahwa rata-rata hasil belajar siswa pada kelas eksperimen lebih tinggi daripada rata-rata hasil belajar pada kelas kontrol, berarti hasil belajar fisika dengan menggunakan model pembelajaran berbasis masalah lebih baik daripada pembelajaran konvensional, sehingga dapat disimpulkan bahwa ada perbedaaan hasil belajar yang signifikan karena pengaruh model pembelajaran berbasis masalah pada materi Listrik Dinamis di SMA Negeri 1 Kualuh Leidong.

\section{KESIMPULAN}

Berdasarkan hasil penelitian dan analisa data serta pengujian hipotesis maka dapat disimpulkan Peningkatan aktivitas belajar siswa selama mengikuti pembelajaran dengan menggunakan model pembelajaran berbasis masalah dari pertemuan I sampai III dengan ratarata nilai seluruhnya adalah 62,07 dengan kriteria penilaian aktif. Berdasarkan hasil analisis perhitungan uji t, terdapat perbedaan yang signifikan akibat pengaruh model pembelajaran berbasis masalah untuk meningkatkan hasil belajar siswa pada materi listrik dinamis di kelas X SMA Negeri 1 Kualuh Leidong T.A 2015/2016. 


\section{SARAN}

Berdasarkan hasil dan kesimpulan dalam penelitian ini, maka peneliti mempunyai beberapa saran, yaitu : Kepada peneliti selanjutnya, pada saat proses pembelajaran berlangsung sebaiknya menambahkan beberapa observer untuk membantu agar pembelajaran siswa lebih terarah dan para observer mampu mengamati siswa serta menilai siswa dalam mengumpulkan data untuk lembar penilaian sikap, keterampilan dan observasi dan lebih memperhatikan efisiensi waktu di setiap fase yang tertuang pada tahap model pembelajaran berbasis masalah.

\section{DAFTAR PUSTAKA}

Abdullah.2013. Sosiologi Pendidikan (Individu, Masyarakat, dan Pendidikan). Jakarta : PT Raja Grafindo Persada.

Huang, K, (2012). Applying Problem-based Learning (PBL) in University English Translation Classes The Journal of International Management Studies, Volume 7 Number 1, April, 2012.

Mariani, E dan Kusumawardani (2014). The Effectiveness of Learning by PBL Assisted Mathematics Pop Up Book Againts The Spatial Ability in Grade VIII on Geometry Subject Matter, International Journal of Education and Research. Volume. 2 No. 8 August 2014.

Turnip, B dan Maidita, N (2015). Pengaruh Model Problem Based Learning Menggunakan Video Pembelajaran Terhadap Hasil Belajar Siswa Pada
Materi Pokok Suhu Dan Kalor

Kelas X SM II SMA N1

Selesai T.P 2014//2015. Jurnal

Ikatan Alumni Fisika

Universitas Negeri Medan.

Volume.1 No. 1 Oktober 2015.

Trianto, (2010), Mendesain Model

Pembelajaran

Inovatif

Progresif, Kencana, Jakarta.

Setyorini, U, dan Subali (2011).

Penerapan Model Problem

Based Learning Untuk

Meningkatkan Kemampuan

Berpikir Kritis Siswa SMP.

Jurnal Pendidikan Fisika

Indonesia. Volume 7. Halaman 52-56. 